\title{
A New Performance Strategy for a Twelve-Station, One-Day York Cycle
}

\begin{abstract}
One of the challenges of the York pageant cycle is understanding how up to fifty pageants could have been performed at each one of ten to seventeen stations within the span of a single day. This paper proposes a new model of York's performance strategy based on staggered starting points. The strategy proposed here offers not only a complete, workable one-day cycle, but also a new breakdown of the pageants into four thematically rich subgroups. An appendix provides a schedule of the full playing day, plus timing calculations and alternative schedules accounting for varying numbers of stations and plays.
\end{abstract}

'For me, the greatest of the York mysteries left over from the Middle Ages has always been the logistics of processional performance of forty-eight wagon episodes at twelve playing stations', wrote Margaret Rogerson in 2009. ${ }^{1}$ Rogerson is questioning the dominant model for the cycle's performance practice, which involves forty-eight wagons moving through York's medieval streets, staging plays at each one of twelve different stations, and doing so within the seemingly impossibly short span of a single day. She is also asking, importantly, why present-day performances have been unable to recreate this maximal procession of every play at every station. The most ambitious effort took place in Toronto in 1998, staging all forty-eight plays in procession in a single day, but at only four stations. Productions in York itself have involved four or five stations and fewer than the total number of plays. Despite a vigorous debate during the 1970s, which contributed to the founding of the Records of Early English Drama (REED), and despite multiple attempts to stage a full York cycle, that logistical mystery has still not been entirely solved. ${ }^{2}$ At issue is the fact that the register's implied evidence for staging practices is fragmentary and spans centuries; the records simply cannot definitively confirm the long-assumed strategy of maximal procession, in which

Arlynda Boyer (arlynda.boyer@mail.utoronto.ca) is a $\mathrm{PhD}$ candidate in the department of English at the University of Toronto. 
every play is performed at every station. Modern attempts to recreate the cycle have, moreover, sparked a rethinking of some of the register's evidence. Rogerson, in particular, has shifted her thinking entirely to a plan in which the plays are performed only at a few key stations, passing through the others without stopping, like a parade float. ${ }^{3}$

Below, I propose a plan that deepens and adds specificity to Rogerson's broad hypothesis while still maintaining performances at every station. My model breaks the plays into four subgroups of twelve or thirteen pageants: the surviving plays, plus two of the three titles for which we have no extant text. Then, I move all the pageants along the parade route with performances at staggered stations: any individual pageant performs at every fourth station, but rather than all the plays starting from the first station at Trinity Priory, some plays begin their cycle at the second, third, or fourth stations (Mickelgate 1, Mickelgate 2, and Ousegate, respectively) and move to every fourth station from that starting point. This model allows every one of the twelve stations to see either twelve or thirteen plays apiece; as it turns out, this plan provides each station with a clear, coherent narrative arc featuring every important element of the entire cycle in terms of creation, nativity, miracles, and the crucifixion. Every play in the cycle is thus performed within a single day of reasonable length, something no other current model offers.

Let us assume that the York organizers aimed to achieve at least four goals:

1. To stage all the plays. The only reason modern recreations give for reducing the number of plays is logistical difficulty. The proposal I offer here makes it both possible and practical to stage every play multiple times within a single day, as the records suggest, and is thus preferable to a model that eliminates plays. This model, moreover, presents flexible ways to reorganize pageants when necessary.

2. To utilize all the stations. I prioritize the active involvement of every station. If some stations saw no performances, but only wagons passing through as if they were parade floats, then how are those stations qualitatively different from any other spot on the street? What makes a station a station - and what causes people to bid for the right to have a station — if not the promise of performance? This model is the first to offer a practical method of presenting performances at every one of the twelve traditional York stations. 
3. To present a coherent biblical narrative following the chronological nature of the story told (from Creation to Doomsday), given that the cycle's ostensible purpose was at least in part spiritual education and edification.

4. To wrap up in one day, since this is the evidence we have from the records. A 1476 order speaks of 'the day of the saide playe', ${ }^{4}$ and a 1484 order speaks of pageants as occurring 'vpon Corpus Cristi daye.' 5 Nowhere does it appear that York's records support multiple days of playing, as was the case in Chester, where a similar cycle was performed over three days.

Proceeding from the assumption that York's medieval performance strategy did satisfy all four goals, I offer a plan that seems the most sensible and time-efficient way to do the same, something that no other existing scheme does. As Rogerson acknowledges, modern recreations have offered strong evidence that performing every play at every one of twelve stations results in an event that cannot realistically wrap up in one day. Eliminating or skipping stations raises questions of which stations, why, and what the point is of designating a station not used as a presentation area. My plan presents not one but four clear narratives, which the structure of the canon seems to support. The cycle can be completely staged in twelve to fourteen hours - an epic day of theatre, to be sure, but an easily achievable one and one comparable to a festival day. This model results in the most plays being staged, at the most locations, in the least amount of time, without sacrificing narrative clarity. Based on available sources, I believe that this model is potentially the new best working theory as to the York cycle's medieval performance strategy. Explaining this concept on paper is tricky, but this plan is easy to understand when seen. To visualize this performance strategy, a short animation is viewable (see Figure 1): https://doi.org/10.12745/et.22.2.3964.

I have also discovered that grouping the plays in this fashion reveals thematic connections and structural resonances that could greatly reward further research. Indeed, there are numerous potential archival, theoretical, and critical spinoffs from this proposed strategy: what does it mean for the audience to see only one quarter of the cycle (and which quarter), assuming that they chose to sit at a single station and remained there all day? If they wandered about, what does it mean to see pageants in a more fragmented, disconnected festival-like atmosphere? Besides the large thematic connections within each proposed subgroup here, are there also linguistic, poetic, gestural, theatrical, guild-related, or doctrinal resonances between pageants so grouped? Although I argue that this strategy is flexible enough to adapt to varying numbers of stations and pageants, I have not been able to consider how textual instability might affect it. All of these questions are worth 


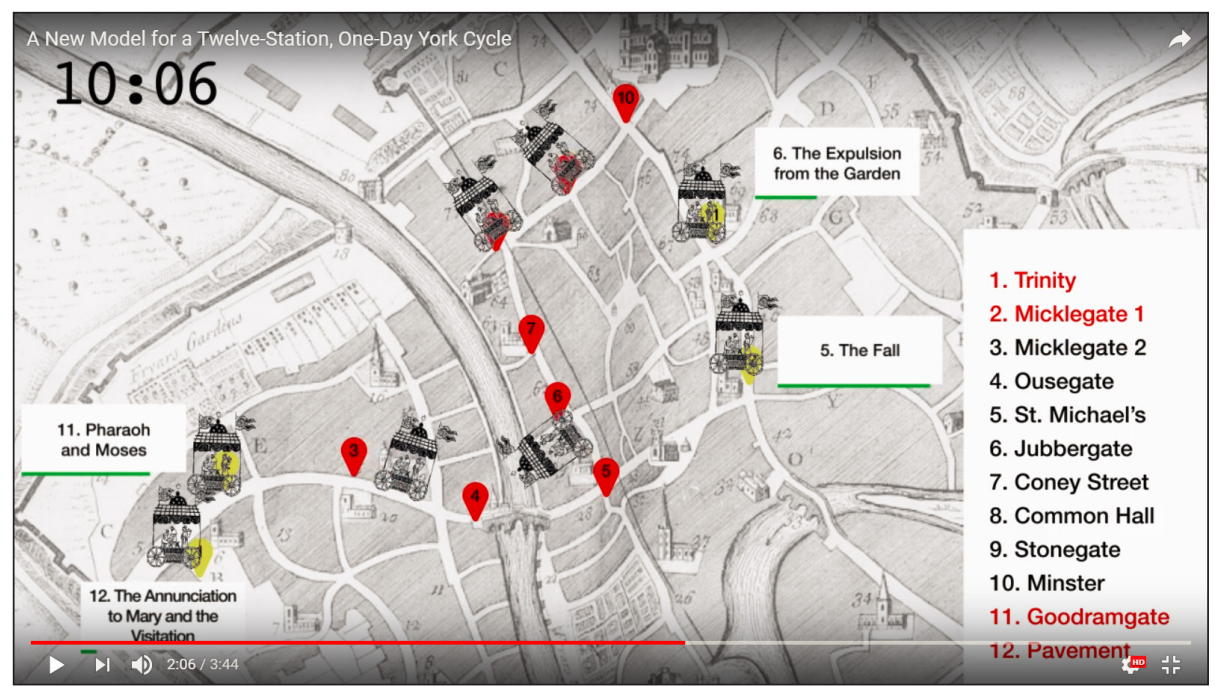

Figure 1. Screenshot of Animation Depicting Pageant Wagons Along Route.

https://doi.org/10.12745/et.22.2.3964. Video created by Joshua D. Brown.

answering, but lie well beyond the scope of a single paper. I propose this strategy with the hope of starting a conversation (and grandly, of perhaps inspiring new productions).

The York records complicate the logistical picture. Rogerson ruefully writes

The York records from that early period do not tell us more than a fraction of what we would like to know and there are no descriptive eye-witness accounts among them; the surviving medieval documents were not written as theatrical records and remain cryptic, awaiting and often defying interpretation. ${ }^{6}$

One major change in interpretation was the assumption of a 4:30 am start time for the pageants. Rogerson (then Dorrell) depended on this time when she created the timetable in which she sought to establish that a processional playing of the cycle in a single day was possible. But Meg Twycross discovered that the time was an overwrite in a later hand, ${ }^{7}$ and could not be considered constant across the time frame. ${ }^{8}$ Twycross also discusses the presence of the common clerk at the first station, doing something called 'keeping the Register.'? Scholars such as Peter Meredith have taken the clerk's presence to mean that he was checking the performances against the accepted text of the pageants, which would require that every play be performed in front of him. ${ }^{10}$ But Rogerson suggests that the clerk's 
task may have been merely to check off plays to ensure that the wagons were all present and in the correct order. Given that York officials did not levy fines for violations of textual fidelity, or even particularly discuss textual fidelity beyond expressing a practical preference for well-spoken actors, and given that the actors they had were not all professionally trained, it seems unlikely that 'keeping the Register' required a full performance to check for textual perfection. Even as early as 1972, Rogerson resisted the implication, drawn later by Meredith, that the clerk's presence at the first station was necessarily proof of performance there, writing that it was 'not clear what [his] duty entailed'. ${ }^{11}$

The assumptions of a 4:30 am start time and that 'keeping the Register' required a textual check are examples of reinterpreted or discarded bits of evidence. Less equivocal is that the eighth station, Common Hall, was where the mayor and other dignitaries typically saw the pageants, suggesting that perhaps any logistical scheme should pay special attention to the pageants presented there. The mayor and council were supplied with three meals during the course of their civic duties, strongly implying an all-day affair. ${ }^{12}$ My proposed plan aims at achieving a performance of all the plays within the most reasonably speedy time possible, but even then my total schedule lasts from 8:00 am to 10:00 pm, from the first play's entrance at Trinity Priory to the final play's exit at the Pavement. More evidence for an all-day duration comes from the city's regulation of food and drink sales and its collection of part of the profits of seating stands erected for viewers at various stations. ${ }^{13}$

In 1972, Dorrell wrote, 'The references to the twelve places and the official banners set up to mark their positions imply that each pageant was to stop and

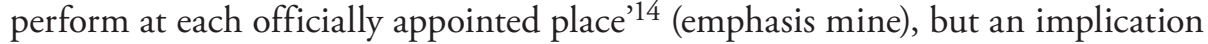
can far too easily harden into orthodoxy. When data is equivocal, slippage tempts, so that one scholar's 'might have' becomes another scholar's 'must have', and over time, when many sophisticated arguments have been built on 'might have', scholarly wording often slips from 'might have' to 'did'. Indeed, David Crouch describes the procession and writes, "This general route was followed throughout the whole of the subsequent life of the Corpus Christi plays, and, during the fifteenth century, every recorded performance, but one, stopped at twelve stations on that route' (my emphasis). ${ }^{15}$ What was an implication is restated as a fact - there is no proof in the records of stopping at every station.

As scholars have suggested in other contexts, the way we now read the cycle may never have been the way anyone saw it. Scholars have imagined that the experience of the York cycle was the experience of seeing all the plays one after another - an epic (even endurance) event of marathon theatre. But nothing in 
the records definitively confirms that belief, and for a marathon that would lie so far beyond the scope of any other known medieval drama, one might expect or at least hope for some piece of evidence to attest to such a spectacle.

\section{Previous Recreations}

The apparent difficulty of maximal staging led Alan Nelson in 1970 to argue that true processional playing was logistically impossible. He left open the question of what was done instead but suggested a fixed-location performance. ${ }^{16}$ Martin Stevens, who maintains that prior to 1426 the plays were presented as nothing more than 'tableaux vivants', ${ }^{17}$ supported Nelson's argument. ${ }^{18}$ With her carefully constructed timetable demonstrating a full playing day at York, Dorrell challenged Nelson's assertion, a position shared by Alexandra F. Johnston. ${ }^{19}$ Dorrell's charts show that processional playing was - just barely — possible, beginning at 5:00 in the morning and ending after midnight, and assuming only two to five minutes to move wagons from one station to the next (through crowds, over bridges and hills, and over unpaved streets). Obviously, even the smallest delay, amplified and multiplied through the stations, would prove disastrous for such a schedule. It was clear by 1972 that an attempt at recreation needed to take place, as the best way to answer the logistical questions. A question worth asking ourselves, however, is whether a playing day of over twenty hours — even if possible — would be practical, or entertaining, or desirable. That the event would be any of the three is not at all apparent, nor from any point of view - that of the performers, that of the audience, or that of the city. In short, whether or not the York guilds could successfully stage a twenty-hour marathon extending beyond daylight at both ends, one wonders why they would do such a thing.

Early recreations, such as York's in 1951, made no effort at using wagons or processional staging. Toronto's first attempt to do so, in 1977, was thwarted by rain. The 2002, 2006, and 2010 cycles at York, and the 1998 cycle at Toronto, did succeed in proving that processional staging worked better than a fixed-stage production. None of them, however, attempted more than five stations. Johnston says of the 1998 Toronto cycle, 'The first general lesson we learned from the daylong production of all forty-eight pageants is that, contrary to much sceptical speculation, it is possible to do them all in one day. ${ }^{20}$ The day ran from 6:00 am to after midnight, although Johnston attributed at least two hours of that time to delays caused by having to share wagons, which would not have been an issue for the medieval guilds, and another forty minutes to modern additions to the text from one performance group. Giving that two hours and forty minutes 
back would mean a performance that ended around 9:30 pm. Thanks to simultaneous playing, playing at twelve stations does not simply take 2.5 times longer than playing at five; nevertheless, it is difficult to see how, if it took fifteen and a half hours - the 6:00 am to 9:30 pm run that would have happened without added delays - to play four stations, eight more stations (that is, all forty-eight plays, at eight more stations each) could have been squeezed into just three or four more hours. The recreations in York have used either four or five stations as well and have been equally time-intensive. ${ }^{21}$ The fact remains that maximal staging has never been successfully replicated. In contrast to Johnston's interpretation of the experiment, Clifford Davidson refers to the Toronto cycle as having 'made evident' the 'impossibility' of performing forty-eight plays at twelve stations and writes that participants were led to speculate that some plays might have been omitted each year. ${ }^{22}$

Seeing the cycle produced has allowed scholars to reapproach old questions from new angles. Rogerson's move away from maximal playing is based largely on modern productions. In Playing a Part in History, she writes:

the Toronto production actually lent weight to Nelson's argument against [the full true processional] method, for although all the episodes were performed over a very long day they were seen not at twelve playing stations but only at four ... The wagon productions directed by Mike Tyler in York in 2002 and 2006 have only served to increase my concern in this regard. Even with careful planning and a strict schedule, the ten and twelve wagons, respectively, took almost seven hours to complete their run through the five, and in 2006 , four, stations. ${ }^{23}$

Part of Rogerson's rethinking lies in her reinterpretation of a 1476 ordinance against playing more than twice. The ordinance itself reads:

And that no plaier that shall plaie in the saide Corpus christi plaie be conducte and Reteyned to plaie but twise ... on the day of the saide playe And that he or thay so plaing plaie not ouere twise the saide day vpon payne of $\mathrm{xl}$ s. to forfet vnto the Chaumbre as often tymes as he or thay shall be founden defautie in the same. ${ }^{24}$

Traditionally, scholars have taken this to be a prohibition against tripling or quadrupling roles, because a pageant might be held up by a performer's inability to move quickly between wagons, to get from one gig to another, as it were. Rogerson suggests that it might also be read to stipulate that no play be performed more than twice. I disagree; for this interpretation to be true — for there actually 
to be a ban on pageants playing more than twice - one would have to believe that for this ordinance, and this ordinance only, the leaders of York suddenly decided to gender the pageants and refer to pageants (rather than people, as the traditional reading has it) as 'he' or 'thay'. 'Plaier' and 'he' do not refer to entire pageants elsewhere in the records, and doing so here is quite unlikely. In my proposed plan, plays perform three times along the route, and I do not believe that this ordinance in any way prohibits such a strategy.

Rogerson now suggests that each play was performed only twice, and the wagons would simply glide through the other ten stations without stopping, like a parade float. As to the logistics, she writes, 'The challenge for the theatre historian is to reconcile the compelling evidence of the documentation from medieval York that it could be done with the equally compelling physical evidence of modern production practice that it could not'. ${ }^{25}$ Her new model is, in her own words, 'privileging' the most important stations - Trinity Priory, St Michael's, Common Hall, the Minster, and the Pavement (that is, stations 1, 5, 8, 10, and 12), writing,

Viable mystery cycles ... are on display at the major stations for the local dignitaries and at the other stations along the route ... It is a leisurely progress combining performance and processional display. Each station sees all the forty-eight wagons go by and interspersed with this procession there is a performance of seven, eight, or nine episodes. ${ }^{26}$

In other words, five stations get pageants and the other seven do not. Cutting the number of stations down to four or five in order to get the pageants finished in one day is what troubles Rogerson about modern recreations, but she elides the fact that her plan functionally accomplishes the same thing. The other stations are notionally present, but if they are not played at, then there is little other than seating and concessions to differentiate them from any other point along the route. The examples she gives, moreover, list only twenty-nine plays. I think her insight about skipping stations is on target, though, and the plan presented here develops and extends her initial hypothesis. Of course, with every proposed scheme, we should ask ourselves what we gain and what we lose by the idea. We lose the idea of being able to see the entire sequence of plays from the creation of the angels to doomsday. There is no station at which that would be possible but it now seems likely that there never was. On the other hand, when the cycle is broken into four play groups, one sees intriguing thematic and structural patterns emerge. 


\section{Planning a Staggered Cycle}

The major innovation of this proposal is the pattern of the station skipping. The first four plays take the first four stations, in reverse order: that is, plays 1-4 play at stations $4-1$ respectively:

'The Creation of the Angels and the Fall of Lucifer'

'The Creation through the Fifth Day' Ousegate (station 4)

'The Creation of Adam and Eve' Mickelgate 2 (station 3)

'The Prohibition of the Tree of Knowledge' Mickelgate 1 (station 2) Trinity Priory (station 1) My playing day begins at 8:00 am, and each wagon steps off from Trinity Priory in ten-minute increments. The first wagon does not stop until it reaches the fourth station, Ousegate, where it begins to play its first performance of the day. Because I allow five minutes' travel time between each station, the first wagon takes until 8:15 (three stations $\mathrm{x}$ five minutes $=$ fifteen minutes) to reach Ousegate, leaving Trinity Priory at 8:00, reaching Mickelgate 1 at 8:05 and passing through without playing, passing through Mickelgate 2 at 8:10, and reaching Ousegate and beginning to play at $8: 15$. The second wagon, starting out from Trinity Priory ten minutes later at 8:10, proceeds through the first Mickelgate station at 8:15, to stop at the second one at 8:20 and begin to play. Although the second wagon started ten minutes later, it has five minutes fewer to travel, so it arrives at Mickelgate 2 at 8:20. The third wagon steps off from Trinity and goes to the very next station, Mickelgate 1, where it begins to play, at 8:25. Finally, at 8:30 the fourth wagon pulls into Trinity and begins to play immediately. All four plays are performed more or less (relative to their run times) simultaneously, each at its respective station. Each play then passes through the next three stations, akin to a parade float, and stops to play at every fourth station.

Once the four plays have finished, they continue in the same order around the route. Leaving room for the three wagons behind it, 'The Creation of the Angels and the Fall of Lucifer' (play, and hence wagon, 1) proceeds to the eighth station, Common Hall; 'The Creation through the Fifth Day' (play 2) takes its place at the seventh station, Coney Street; 'The Creation of Adam and Eve' (play 3) at Jubbergate, the sixth station; and 'The Prohibition of the Tree of Knowledge' (play 4) at the fifth station, St Michael's. Once finished at those stations, the quartet makes one final move, which takes the first play to the twelfth and final station, 
with the remaining three arrayed behind. That means that every station has seen a play, and that each play is performed three times and finished. The travel time builds in flexibility, and the ten-minute increments at Trinity Priory keep each pageant from stepping on its predecessors' toes. While the first four plays have moved around the route and reached the end, the second four (plays and wagons $5,6,7$, and 8) have been steadily launched and are now filling stations $5-8,{ }^{27}$ and the four following (plays 9, 10, 11, and 12) are occupying the first four stations. ${ }^{28}$ And so on, to the end of the day.

That is a bird's-eye view of the route. From a station's view, the day looks like this: every fourth play stops at your station, performs for its 5-25-minute length, and moves away. Before the next pageant will begin, there will be, very roughly, a fifteen or twenty-minute break, but during that time, the three wagons that your station is not seeing will be proceeding along the route like parade floats, passing through but not stopping, so if you are an audience member who decides to take up a place at one station and remain there all day, then your experience of the day's cycle is that something is happening in front of you every few minutes, and every fifteen or twenty minutes, that 'something' is a pageant - not to mention that the festive nature of the day means that socializing, eating, drinking, and other entertainments fill the time. Thus, the cycle is broken out into four groups of a dozen or thirteen plays each, playing three times, at every fourth station (see Table 1). A festival-style experience of wandering the streets, pausing at any pageant wagon that looked interesting, or following one wagon along its entire route, perhaps because friends or family members were acting there, was equally available.

\section{Table 1. Plays by Group}

\begin{tabular}{|c|c|c|c|}
\hline \multicolumn{2}{|c|}{ Ousegate/Common Hall/Pavement Group: } & \multicolumn{2}{|c|}{$\begin{array}{l}\text { Mickelgate2/Coney Street/Goodramgate } \\
\text { Group: }\end{array}$} \\
\hline 1. & $\begin{array}{l}\text { 'The Creation of the Angels and } \\
\text { the Fall of Lucifer' }\end{array}$ & 2. & $\begin{array}{l}\text { 'The Creation Through the Fifth } \\
\text { Day' }\end{array}$ \\
\hline 5. & 'The Fall' & 6. & 'The Expulsion from the Garden' \\
\hline 9. & 'The Flood' & 10. & 'Abraham and Isaac' \\
\hline 13. & 'Joseph's Troubles about Mary' & 14. & 'The Nativity' \\
\hline 17. & 'The Purification of the Virgin' & 18. & 'The Flight to Egypt' \\
\hline 21. & 'The Baptism of Christ' & 22. & 'The Temptation in the Wilderness' \\
\hline
\end{tabular}




\begin{tabular}{|c|c|c|c|}
\hline \multicolumn{4}{|c|}{ Table 1 continued } \\
\hline \multicolumn{2}{|c|}{ Mickelgate 1/Jubbergate/Minster Group: } & \multicolumn{2}{|c|}{ Trinity Priory/St Michael's/Stonegate Group: } \\
\hline $23 \mathrm{~A}$. & 'The Feast in Simon's House' & 24. & $\begin{array}{l}\text { 'The Woman Taken in Adultery } \\
\text { and the Raising of Lazarus' }\end{array}$ \\
\hline 27. & 'The Last Supper' & 28. & 'The Agony and the Betrayal' \\
\hline 31. & 'The Trial before Herod' & 32. & 'The Remorse of Judas' \\
\hline 35. & 'Crucifixio Christi' & 36. & 'Mortificacio Christi' \\
\hline 39. & $\begin{array}{l}\text { 'The Appearance of Christ to Mary } \\
\text { Magdalen' }\end{array}$ & 40. & 'The Travelers to Emmaus' \\
\hline 43. & 'Pentecost' & 44. & 'The Death of Mary' \\
\hline 47. & 'Doomsday' & & \\
\hline \multicolumn{2}{|c|}{ Mickelgate 1/Jubbergate/Minster Group: } & \multicolumn{2}{|c|}{ Trinity Priory/St Michael's/Stonegate Group: } \\
\hline 3. & 'The Creation of Adam and Eve' & 4. & $\begin{array}{l}\text { 'The Prohibition of the Tree of } \\
\text { Knowledge' }\end{array}$ \\
\hline 7. & 'Sacrificium Cayme et Abell' & 8. & 'The Building of Noah’s Ark' \\
\hline 11. & 'Pharaoh and Moses' & 12. & $\begin{array}{l}\text { 'The Annunciation to Mary and } \\
\text { the Visitation' }\end{array}$ \\
\hline 15. & 'The Offering of the Shepherds' & 16. & $\begin{array}{l}\text { 'Herod Questioning the Three } \\
\text { Kings and the Offering of the } \\
\text { Magi' }\end{array}$ \\
\hline 19. & 'The Massacre of the Innocents' & 20. & 'Christ and the Doctors' \\
\hline $22 \mathrm{~A}$. & 'The Marriage in Cana' & 23. & 'The Transfiguration' \\
\hline 25. & 'The Entry into Jerusalem' & 26. & 'The Conspiracy' \\
\hline 29. & $\begin{array}{l}\text { 'The Trial before Cayphas and } \\
\text { Anna' }\end{array}$ & 30. & 'The First Trial before Pilate' \\
\hline 33. & 'The Second Trial before Pilate' & 34. & 'The Road to Calvary' \\
\hline 37. & 'The Harrowing of Hell' & 38. & 'The Resurrection' \\
\hline 41. & 'Doubting Thomas' & 42. & 'The Ascension' \\
\hline 45. & $\begin{array}{l}\text { 'The Assumption of the Virgin' } \\
\text { ('Thomas Apostolus') }\end{array}$ & 46. & 'The Coronation of the Virgin' \\
\hline
\end{tabular}

A look at the timing spreadsheet (Table 2) reveals that this apparently complex plan is, on the ground, the simplest and most straightforward choice, with the playing times (in boldface) coiling like a maypole ribbon among the cells. Each individual play spends between ninety minutes and two hours 'in the field', from its entry at Trinity Priory to its exit at the Pavement. This is a manageable length of time for actors, in a way that performing twelve (up to seventeen) times, once at every station, is not manageable. Each play runs the entire route: in procession for three stations, playing for the fourth. Every station is busy throughout 


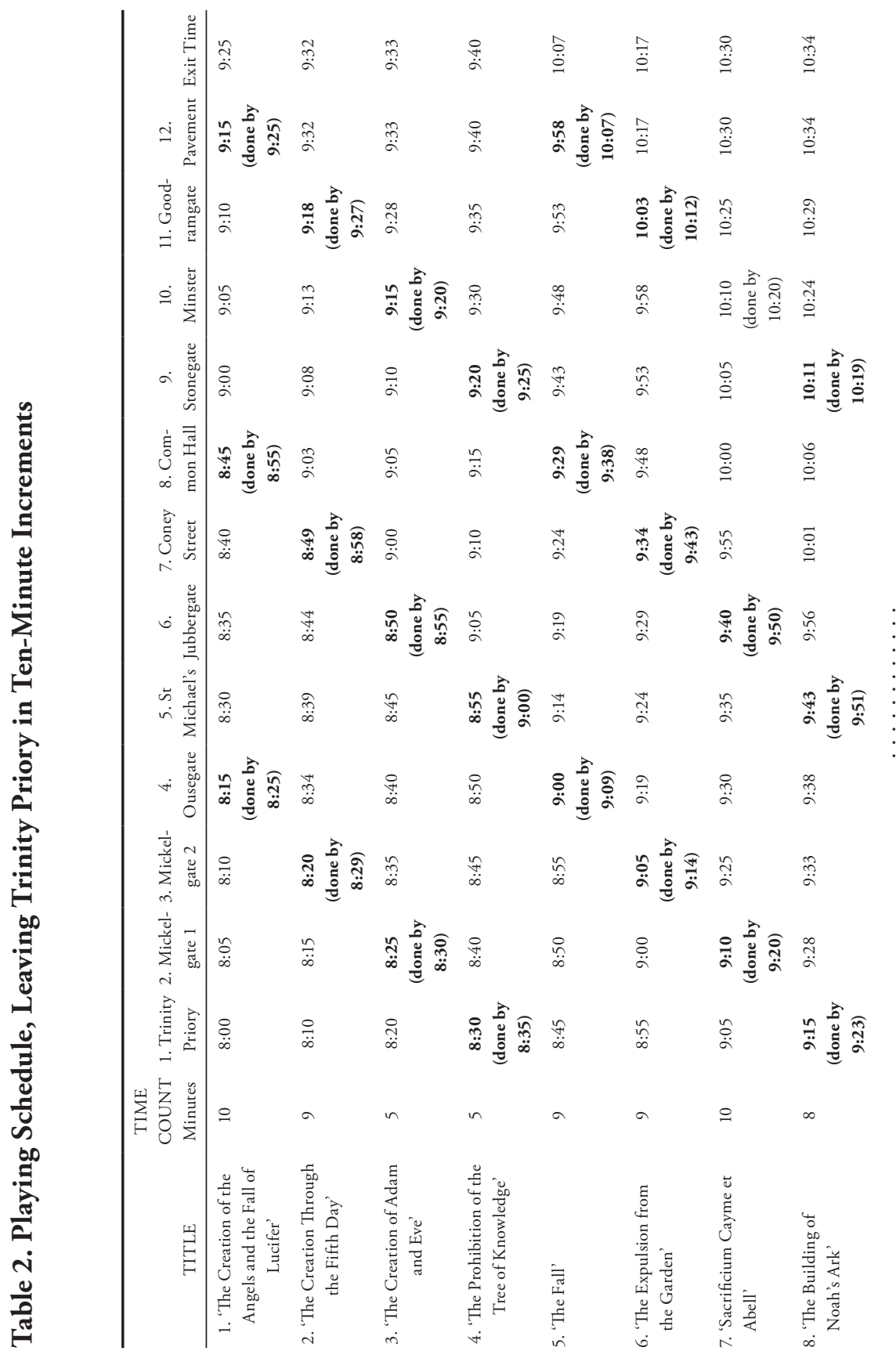




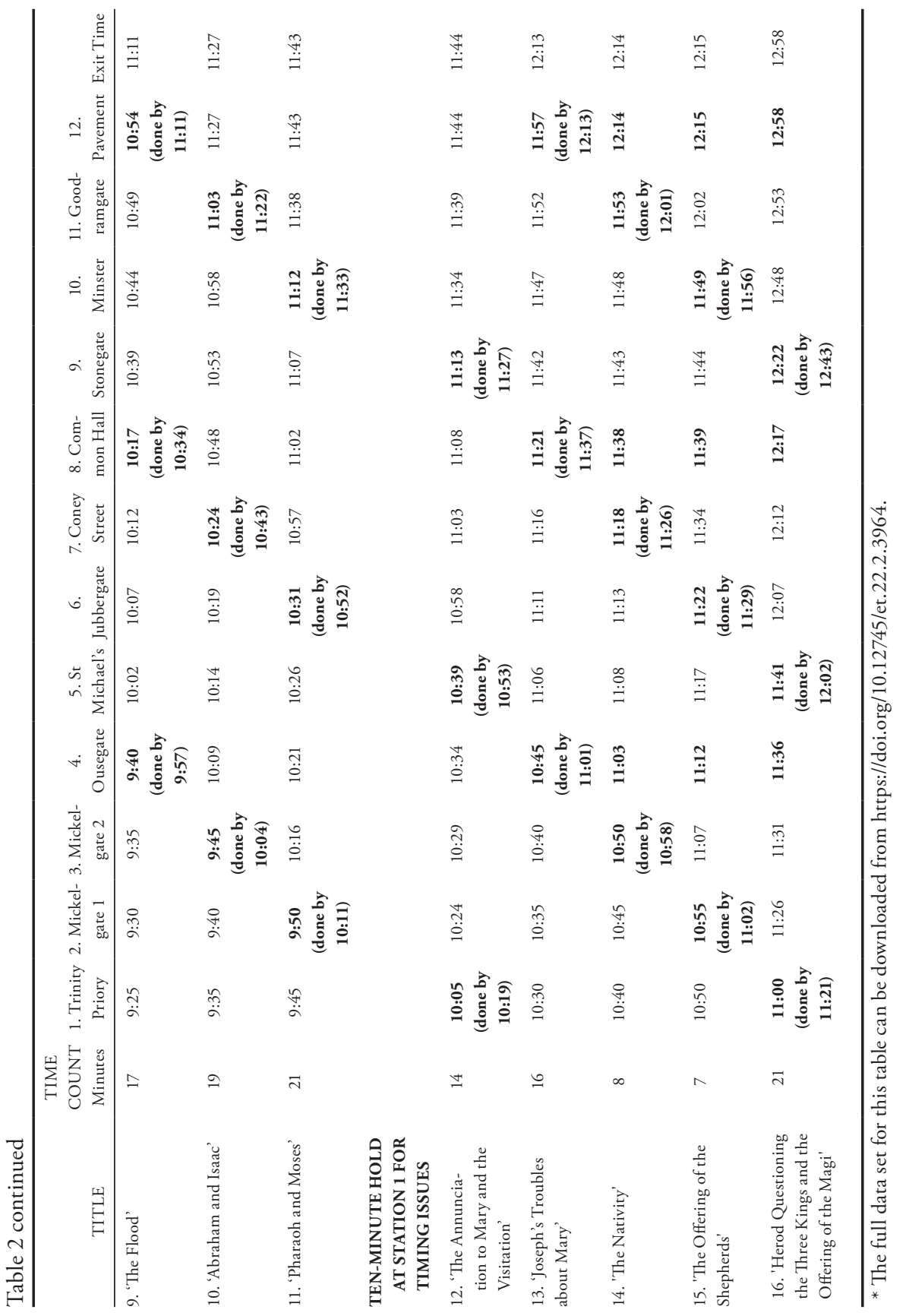


the day, with both pageants and processions. Finally, all the stations are finished within two hours of each other, as opposed to the traditional processional model in which Trinity Priory was finished nearly eight hours before the Pavement was. This consideration alone yields a far more workable festival day than a traditional maximal playing scheme.

The biggest scheduling problem is still the one that first attracted my curiosity - long pageants next to short ones. There is no getting around the fact that when a long play precedes a short one, the short one will have to wait repeatedly on the longer one to finish before it can move on. I managed the difficulty by inserting two ten-minute 'holds' and one fifteen-minute 'hold', between plays 11 and 12 ('Pharaoh and Moses' and 'The Annunciation to Mary and the Visitation'), plays 17 and 18 ('The Purification of the Virgin' and 'The Flight to Egypt'), and plays 25 and 26 ('The Entry into Jerusalem' and 'The Conspiracy'), which may be seen in the appendix. ${ }^{29}$ By holding the latter plays at Trinity Priory — and only at Trinity Priory — the preceding longer plays are allowed a head start that tends to even out their time differentials.

This is not exactly endurance theatre for any individual actor, but it would still be an epic day of theatre. In sum, the day includes forty-nine plays (including the lost 'The Marriage in Cana' and 'The Feast at Simon's House'), performed three times each, for a total of nearly one hundred fifty performances, spanning twelve locations, in a citywide celebration of Corpus Christi.

\section{Thematic Implications}

When I was discussing establishing the timing of the York cycle with the American Shakespeare Center's Jay McClure, he commented that my plan made the York cycle look 'like modern environmental theatre (like Sleep No More) ... part of the fun is knowing that there's no way you can see everything. ${ }^{30}$ Another good analogy is a fringe festival, where an attendee must choose which competing performances to see. The surprising thing (and, to me, a convincing thing) that appeared when I broke the plays up into these groups was this: not only does every station get a coherent narrative, but

- Every station gets one pageant with a creation scene or a scene in the Garden of Eden;

- Every station gets a play about the patriarchs;

- Every station gets one play centering on Mary's pregnancy and the Nativity; 
- Every station gets the performance of a miracle;

- Every station gets either the betrayal or a trial;

- Every station gets one pageant concerning the crucifixion;

- Every station gets one pageant about the risen Christ;

- Every station gets one pageant about Mary's death and/or the return of Christ.

What this means, of course, is that a spectator need not see every pageant in order to understand the story told, nor are they required to interpret or to fill in narrative or chronological gaps via the wagons which pass through their station without playing. Rather, each and every station presents a clear, effective narrative that spans from the creation of the earth to the return of Christ and does so using only one quarter of the plays in the total cycle. (One may peruse Table 1 again for a confirmation of these narrative elements across groups.) The four groups, moreover, seem to offer potential — and highly flexible — thematic clusters. The Ousegate/Common Hall/Pavement group appears particularly focused on sin and punishment, including not one fall but two (Lucifer's and man's), 'The Flood', 'Crucifixio Christi', and 'Doomsday'. In my proposal, these would be the group of plays seen by the mayor and the city council, and also played at the Pavement, the place of public execution. The Mickelgate 2/Coney Street/Goodramgate group seems focused on suffering and the painful acceptance of God's will: this group has 'The Expulsion from the Garden', 'Abraham and Isaac', 'The Agony and the Betrayal', and 'Mortificacio Christi'. The Mickelgate 1/Jubbergate/Minster group stages a psychomachia between skepticism and belief, with 'Sacrificium Cayme et Abell', 'Pharaoh and Moses', and 'Doubting Thomas'. Finally, the Trinity Priory/ St Michael's/Stonegate group shows obedience rewarded, featuring 'The Building of Noah's Ark', 'The Annunciation to Mary and the Visitation', 'Herod Questioning the Three Kings and the Offering of the Magi', 'The Transfiguration', 'The Resurrection', 'The Ascension', and 'The Coronation of the Virgin'. On a more entertainment-oriented level, most of the pageants with overt comedy, as well as the most spectacular pageants, strikingly wind up clustered into a single group, the Ousegate/Common Hall/Pavement group — the group of pageants likely enjoyed by the town's most prominent citizens. ${ }^{31}$ Eliminating 'Fergus' ('The Funeral of the Virgin') enables the location of 'Doomsday' in this play group. In 1431, the Masons asked to be relieved of the pageant because it evoked 'more noise and laughter than devotion'. ${ }^{32}$ Cutting it shifts all the following plays by 
one group, moving 'Doomsday' out of the Mickelgate 2/Coney Street/Goodramgate group and into the cycle's most prestigious play group. That these thematic resonances and this one-major-element-per-station deep structure emerged organically when staging is envisioned this way was striking and seems too meaningful to be completely accidental. Indeed, they emerge only if the starting stations are staggered in this way. This pattern is why I believe that the plan presented here could be the new best working theory of York's performance strategy.

Then again, this option is only one hypothetical set of possibilities among many. I do not argue here that my plan was necessarily precisely what was done, only that such a plan of staggered stations is achievable and would stand as the simplest, most straightforward, and most practical way of presenting the full cycle at York in a day, satisfying all the archival witnesses. It would be entirely possible to rearrange the plays so as to create different groupings for any given station, with different themes or resonances, without losing the sense of coherence or completion that each station provides.

In 1966, V.A. Kolve outlined figural resonances between plays, citing ways in which Old Testament episodes prefigured episodes in the life of Christ and arguing that the patterns of figural resonance explained how pageant cycles across England seem to converge on the same or similar episodes. Kolve drew links between Flood narratives ('The Flood' in the York cycle) and the baptism of Christ, as well as links between the flood and Doomsday. ${ }^{33}$ Under the plan outlined here, all three pageants ('The Flood', 'The Baptism of Christ', and 'Doomsday') fall into the important Ousegate/Common Hall/Pavement subgroup, making the resonances visible to an audience who saw them in fairly close proximity to one another (i.e., within a sub-cycle of thirteen plays rather than more widely scattered among nearly fifty plays). Kolve also linked the Abraham and Isaac story to Jesus in the Garden of Gethsemane; ${ }^{34}$ both of York's versions of those stories ('Abraham and Isaac' and 'The Agony and the Betrayal') are found in the Mickelgate 2/Coney Street/Goodramgate group. Another of Kolve's figural connections found in this subgroup is 'The Flight into Egypt' and 'Mortificacio Christi' ${ }^{35}$ Finally, the Mickelgate 1/Jubbergate/Minster group sees the Kolve-connected 'The Exodus' (play 11, 'Pharaoh and Moses') and 'The Harrowing of Hell'. Not all of Kolve's connected plays fall so neatly into my proposed subgroups, but a remarkable number of them do, meaning that if Kolve and I are correct, then narrative and symbolic cohesion were maximized within the sub-cycle structure.

Nothing in York's civic records explicitly contradicts performances staggered by station, nor do they support any other model more strongly (which is to say, there is no definitive evidence of any performance strategy in the records — if lack 
of evidence is a weakness of this model, then every other proposed model, including the assumed one of maximal procession, shares this weakness equally). A few records read in slightly different ways than they have been, moreover, might lend the scheme further support. A 1394 order states

'Concordatum est quod omnes pagine corporis christi ludent in locis antiquitus assignatis \& non alibi sed vt sicut premunientur per Maiorem Ballivos \& Ministros suos vt si qua pagina incontrarium fecerit gentes artificij dicte pagine soluent ad opus communitatis in camera maioris vj s. viij d'36

(It was agreed that all the pageants of Corpus Christi shall play in the places appointed [in] ancient times and not elsewhere, but just as they shall be prearranged by the Mayor, the Bailiffs, and their officers, so that if any pageant does otherwise, the members of the craft of the said pageant shall pay $6 s .8 \mathrm{~d}$. in the chamber of the Mayor for the use of the commons. ${ }^{37}$ )

The REED translation, given above, renders the Latin original as 'as they shall be prearranged by the Mayor'. Read one way, it means simply that the stations are prearranged and that no extraneous, non-station stops are allowed. But it seems unlikely that a wagon already committed to several hours of tightly-scheduled playing would want to make a thirteenth, fourteenth, or fifteenth stop (much less an eighteenth or nineteenth). There might be, though, a far greater temptation for actors still fresh after only one or two performances to stop at an already-marked station, with a waiting, receptive audience, despite the fact that that station is not one of the three at which their particular pageant is scheduled to appear. Playing at the wrong station would not only wreck the carefully-planned timetable just as much as making extra stops would, but more importantly, it also would throw off the arc of the biblical narrative presented at each station and could sow confusion among all the following wagons. This order could be forestalling that possibility, by ordering the pageants to limit themselves to their appointed stations, hence the sternly-worded prohibition and the fine. In 1484, four men were hired to organize the pageants:

Item the same xxviij day of Septembris it was agreed by thassent and consent of be Counsell afore named that [blank] shald haue for thair reward in labouring about the settyng forward and ordoring of the pageantes vpon Corpus Cristi daye by the handes of the Chaumbrelayns vj s viiij d. ${ }^{38}$ 
Traffic managers might well have been necessary no matter what, given the scope of the cycle, but they are much more necessary if pageants do not simply tromp from station to station one after another, in order. If plays appear at staggered stations, then it would be especially wise, even necessary, to have traffic managers to ensure that each pageant stays on its correct schedule of stations. Notably, there were four men hired in 1484 , and there are four sub-cycles proposed here, potentially putting one man in charge of each play group.

Both orders, ninety years apart, refer to 'prearranging' and 'ordering'. The usual interpretation has been one of putting things in order in the sense of making them run smoothly, but I believe there is a suggestion here that the order in which the plays ran had some internal flexibility. Plays could be moved around so that stations did not see the same pageants year after year, or to create themes, which may have been a prerogative of the mayor's office. Liberty Stanavage writes that the Ordo paginarum 'would be copied out each year and sent to the guilds to remind them of the proper order of the plays. ${ }^{39}$ Such a yearly listing would be all the more needed — and would serve as rather more than a mere 'reminder' — if the order changed from year to year. The structure allows for easy reordering. If there were a desire to cycle all the plays through all the stations over a four-year span, then the sub-cycles can be moved wholesale from one group to another. In order to create different groups of plays, one could, for example, simply swap a miracle play from one group with a miracle play from a different group. The subgroup structure creates clear, interchangeable 'slots' for each narrative element. Finally, although I am offering only the lightest of conjectures, a 1396 entry in the York account book records the expenditure of four shillings for 'the staining of four pieces of cloth for the fabric of the pageant'. ${ }^{40}$ This fabric might have been needed for any purpose, but it hints at a possibility: amid the boisterous crowds of a feast day, with citizens of varying levels of literacy and numeracy, what easier way to keep pageant wagons to an every-fourth-station schedule than by colorcoding the banners at each station?

\section{Variability in the Cycle}

The plan proposed here may seem like an intricate puzzle, thrown completely off if any single piece were to go missing, but in fact the scheme is flexible enough to account for changes to the cycle over time. Stations could, for example, range in number from ten to seventeen. Playing at sixteen stations means only that every play group performs four times instead of three over the course of the day, stopping as usual at every fourth station from a staggered beginning. Sixteen is 
the simplest variant, sixteen still being a multiple of four. But playing at ten or seventeen stations is no more difficult. With ten stations, the same pattern is maintained, but some play groups perform only twice, while others perform three times (Table 3). With seventeen stations, all the subgroups perform four times, with only the Trinity Priory/St Michael's/Stonegate group performing once more, for a total of five times on their route through the city (Table 4). Having seventeen stations is the most demanding schedule of this scheme, but five performances is still well within the realm of comfort for most actors in terms of vocal and physical stamina, whereas stopping at every one of seventeen stations seems physically impossible for actors as well as utterly incapable of being completed within a single day. In other words, with this proposal the staggering of the station starts is what matters, and the number of stations makes literally no difference to how the pageants play out — each station still sees a coherent chronological narrative of twelve or thirteen plays apiece. So this proposal can easily manage all the variability in the number of stations recorded in the York accounts.

But what of removing plays? In 1535, the York cycle was not run, being replaced instead by the Creed Play. Guilds turned over the funds designated for their pageants to the city, and the York account books record the income received from each guild. Only thirty-two guilds — and thus pageants — are listed. Rogerson suggests that had the cycle been performed that year, it might have consisted of only those thirty-two episodes, which she lists. ${ }^{41}$ This does alter the narratives presented at each station, although they are still chronological and still more or less complete. In drafting a schedule (Table 5), I retain twelve stations, as that number is the most common number of stations across the cycle's long history. Thirty-two plays yield four subgroups of eight pageants apiece, performed three times each in the same staggered stations and the same subgroups as my proposed plan. The truncated cycle that emerges has a clearer, sharper focus on the life of Christ, as the Old Testament episodes are the ones most heavily cut. We can cut episodes while still retaining a staggered-station planning scheme and subgroups. Perhaps the important thing to remember is that the cycle was not performed in 1535, so Table 5 represents a performance event that never took place. Even the hypothetical 1535 list, however, yields one story set in the garden of Eden for each subgroup, one pageant about the birth and youth of Christ, a perfectly even distribution of trial plays, and so on.

Another change in the number of plays was made between 1547 and 1554, when the three remaining pageants about Mary were removed from the schedule ('The Death of Mary', 'The Assumption of the Virgin' ['Thomas Apostolus'], and 'The Coronation of the Virgin', 'Fergus' ['The Funeral of the Virgin'] having 


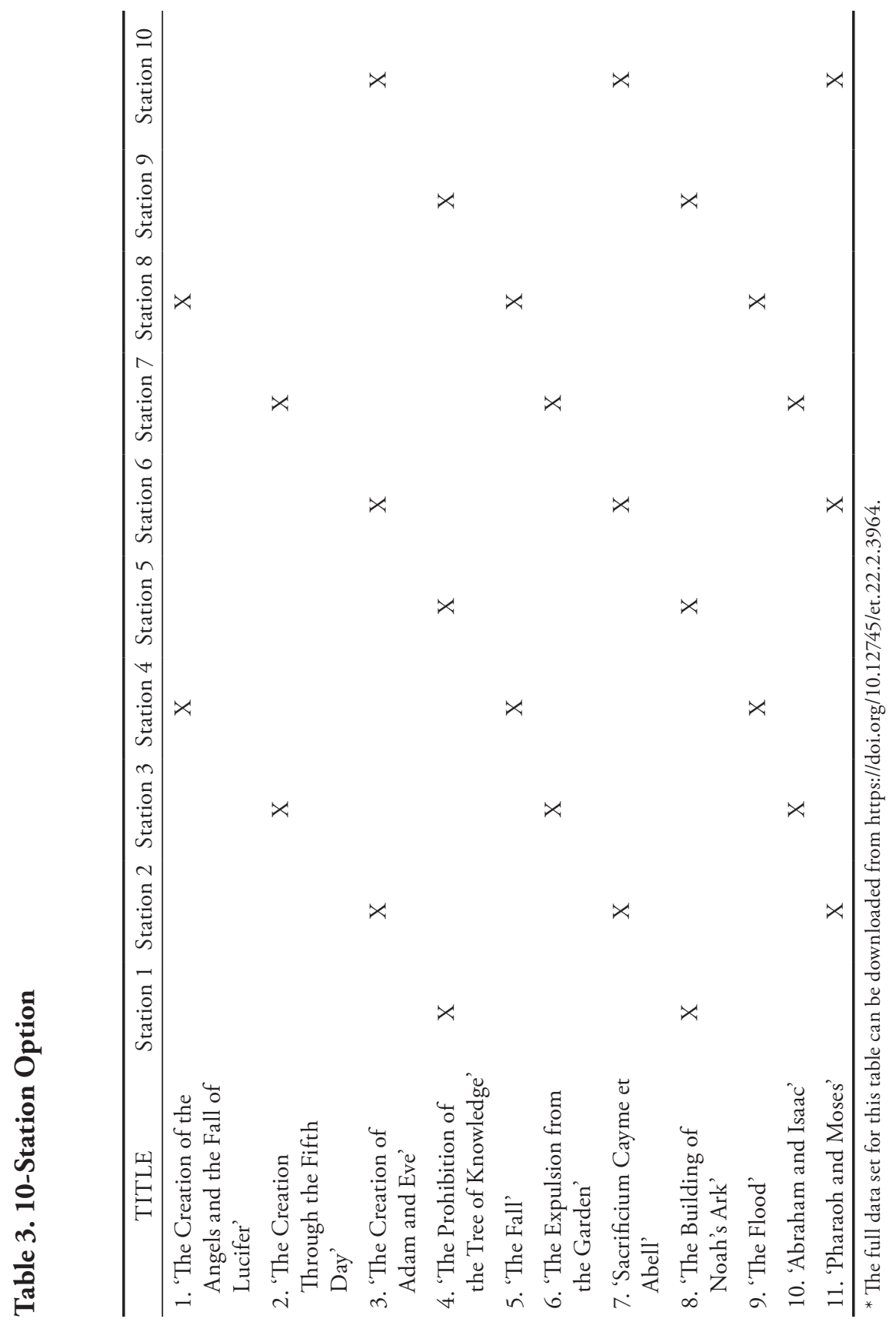




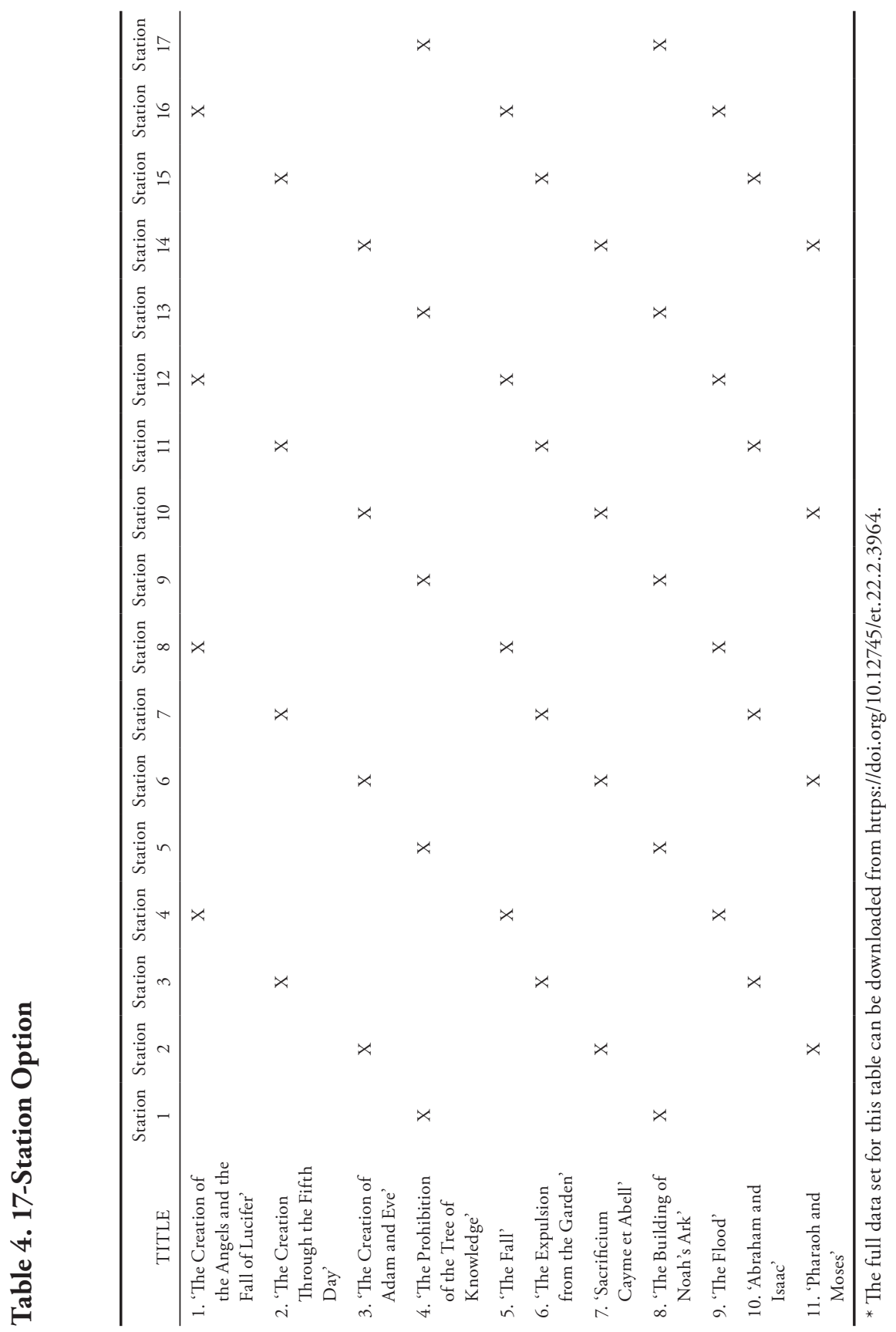




\section{Table 5. 1535 Plays Only}

\section{Ousegate/Common Hall/Pavement Group:}

1. 'The Creation of the Angels and the Fall of Lucifer'

7. 'Sacrificium Cayme et Abell'

16. 'Herod Questioning the Three Kings and the Offering of the Magi'

22. 'The Temptation in the Wilderness'

26. 'The Conspiracy'

30. 'The First Trial before Pilate'

36. 'Mortificacio Christi'

43. 'Pentecost'

\section{Mickelgate 1/Jubbergate/Minster Group:}

$5 . \quad$ 'The Fall'

12. 'The Annunciation to Mary and the Visitation'

20. 'Christ and the Doctors'

24. 'The Woman Taken in Adultery and the Raising of Lazarus'

28. 'The Agony and the Betrayal'

33. 'The Second Trial before Pilate'

$38 . \quad$ 'The Resurrection'

45. 'The Assumption of the Virgin' ('Thomas Apostolus')

\section{Mickelgate 2/Coney Street/Goodramgate Group:}

3. 'The Creation of Adam and Eve'

10. 'Abraham and Isaac'

19. 'The Massacre of the Innocents'

23. 'The Transfiguration'

27. 'The Last Supper'

31. 'The Trial before Herod'

37. 'The Harrowing of Hell'

44. 'The Death of Mary'

Trinity Priory/St Michael's/Stonegate Group:

6. 'The Expulsion from the Garden'

13. 'Joseph's Troubles about Mary'

21. 'The Baptism of Christ'

25. 'The Entry into Jerusalem'

29. 'The Trial before Cayphas and Anna'

35. 'Crucifixio Christi'

40. 'The Travelers to Emmaus'

47. 'Doomsday' 
already been abandoned). As they occupy the same 'slot' in each subgroup, such a move would cause no disruption at all to the overall strategy, simply ending the narrative one pageant earlier and leaving most subgroups with eleven pageants rather than twelve. This model is sufficiently flexible to handle wide variance in both the number of stations and also in the number of plays presented, whereas proponents of maximal procession have struggled to show how that model could handle a one-day performance of pageants at all twelve stations and have never even attempted to show how it might have handled seventeen stations in a twentyfour-hour span. ${ }^{42}$ We ought always to apply the principle of Occam's razor to a performance strategy for a festival as complicated and with as many literally moving parts as the York cycle. I would argue that despite the trickiness of explaining it on paper, in practice the flexibility, the full station involvement, and the fourteen-hour total time of the strategy proposed here means that this plan is the simplest solution.

This project has been an exercise in seeing what is not there: specifically, explicit confirmation in the civic records of sequential playing at every station, and also the need to visualize any given pageant 'missing' three out of every four stations. The final piece of the puzzle, the thematic and structural coherence of each play group, only emerged because of one more thing that normally is not there: the inclusion of two of the three plays without extant texts. Had I not included them, then the way that each play group forms its own mini-cycle from creation to doomsday would not have become apparent. Rather, everything would have been the same up to play 22 ('The Temptation in the Wilderness'), but if 22A ('The Marriage in Cana') had been skipped, then everything after that point would have been off by a notch - and then off still more with the exclusion of 'The Feast in Simon's House' ('Fergus' affects little, as it falls near the end of the cycle, and its excision, as noted, benefits the most prominent play group). Future productions of the cycle, if they choose to attempt this scheme, might consider commissioning plays to fill at least the two spots in the middle of the cycle, or keeping the play groups together regardless of gaps where plays are missing. An ambitious staging of the entire cycle, using all twelve stations according to my proposal, would offer practical evidence of its feasibility.

I believe that this plan, initially conceived as a solution for the logistical nightmare of the York cycle, might yield rewarding new insights into play groups. In 1991, David Crouch wrote, 'The problem of timing seems never to have been satisfactorily solved' (98). ${ }^{43}$ This paper offers one more attempt to solve a fivehundred-year-old mystery, and in so doing it may point the way toward a new paradigm for understanding the plays. 


\section{Appendix. A Note on Calculating Times}

The impetus for creating the model proposed herein was the desire to imagine a workable performance strategy that could realistically occur in one day. That necessitated a consideration of the timing of every individual play. In 1970 Alan Nelson wrote that 'experience or experiment' showed the difficulty of performing poetry expressively at much more than 1,000 lines an hour (309-10). Margaret Dorrell accepted his timing and used it in her own calculations. Nelson's timing, and by extension Dorrell's, works out to 16.66 lines per minute (lpm); both relied on this time estimation in their debate over whether or not the cycle can be concluded in a single day. By way of comparison, the Royal Shakespeare Company performs at roughly $15 \mathrm{lpm}$, and the American Shakespeare Center in Virginia uses $20 \mathrm{lpm}$ as a rule of thumb.

Scott Kaiser of the Oregon Shakespeare Festival (OSF) initially used a method devised by actor and stage manager Ed Brubaker. The Brubaker method works out to an equation of 'line count x .06 = playing time in minutes'. Because the OSF now creates scripts in Microsoft Word, it became easier to get a word count rather than a line count. Kaiser combined data from fourteen OSF productions over five years, covering, as he says, 'hundreds of different actors, each with his or her own idiosyncratic rate of speaking' and he arrived at 135 words per minute.* But there are methods finer still. Jay McClure of the American Shakespeare Center uses the rate of syllables per minute. For Shakespeare, because most of his lines are in iambic pentameter, 20 lines per minute consistently yield 200 syllables per minute. I counted syllables per line across approximately twenty of the York plays, taking chunks of dialogue from different places in the play and from different types of characters (male, female, high status, low status, divine, and demonic), and arrived at an average syllable-per-line count of 8.1 syllables per line (rounded down to 8 ).

Lastly, Denis G. Jerz built a website that allowed users to design their own York pageant cycles. The site, built in 1999, is no longer fully functional in all browsers, but surviving is his dataset of running times for many of the pageants produced in Toronto in $1998 .^{* *}$ That gave me a grand total of five possible, and highly divergent, time counts for most of the plays. To arrive at my play lengths,

* Scott Kaiser, 'Estimating the Playing Time of a Shakespearean Text', Wayback Machine, https://web.archive.org/web/20160729235301/http://scottkaisershakespeare.com/pdf/essays/ kaiser-estimating-play-time.pdf.

** Dennis G Jerz, Understanding The Computer Program (PSim) (1999), last modified 17 November 1999, http://jerz.setonhill.edu/resources/PSim/about.html. 
I averaged all five together where I had Jerz's measurements, and the other four methods where I did not. Only a few of the pageants from York itself are available online. They seem, for unknown reasons, to tend to run slightly faster than their 1998 Toronto counterparts, but there were too few available to make them part of my calculations.

Thus, for example, 'The Creation of the Angels and the Fall of Lucifer' times out at 9.6 minutes via the Brubaker method, 10.24 minutes with Kaiser, 6.4 minutes via the syllable method, 8 minutes even by the $20 \mathrm{lpm}$ method, and Jerz records it as taking 12.25 minutes in the Toronto performance. I did not want to create either an artificially short playing day or an artificially long one, so I averaged all of them together for a run time of 9.3 minutes, rounded to 10. I rounded every play upward to the next whole minute, reasoning that I would rather err on the side of too much time rather than too little, and that getting into position, resetting stage machinery, music, and stage business might take time that I could not otherwise account for. 


\section{Notes}

I would like to thank Matt Sergi and Sandy Johnston of the University of Toronto for their feedback, wisdom, kindness, scepticism, and support; Joshua A. Brown for creating with me a movie file to visualize the movement of pageant wagons; Christina M. Fitzgerald for organizing the New Voices in Early Drama Studies panel at the 52nd International Medieval Congress in Kalamazoo, and the panel participants and audience for their questions and comments, especially Gloria J. Betcher; and James Rogauskas for patiently helping me think through several iterations of timetables, station staggering, and conference presentations.

1 Margaret Rogerson, Playing a Part in History: The York Mysteries, 1951-2006 (Toronto, 2009), 197, https://doi.org/10.3138/9781442688803.

2 For a survey of the debate over staging the plays, see James F. Hoy, 'The Staging Time of the York Cycle of Corpus Christi Plays', The Emporia State Research Studies 21.3 (1973), 5-22. For an account of the early years of REED, see Alexandra F. Johnston, 'The Founding of Records of Early English Drama', https://doi.org/10.3138/9781442627383-003, and Sally Beth MacLean, 'Birthing the Concept: The First Nine Years', https://doi.org/10.3138/9781442627383-004, both in REED in Review: Essays in Celebration of the First Twenty-Five Years (Toronto, 2006).

3 Rogerson's turn to a non-consecutive model came in Playing a Part in History.

4 Johnston and Rogerson, eds, REED: York, 2 vols (Toronto, 1979), 1.109.

5 Ibid., 135.

6 Margaret Rogerson, 'ReED York, Volume 3, The "Revivals", in 'Bring furth the pagants: Essays in Early English Drama Presented to Alexandra F. Johnston, ed. David N. Klausner and Karen Sawyer Marsalek (Toronto, 2007), 137, https://doi.org/10.3138/9781442684096-008.

7 Meg Twycross, 'Forget the 4.30 a.m. Start: Recovering a Palimpsest in the York Ordo paginarum', Medieval English Theatre 25 (2003), 103.

8 I chose my start time of 8:00 am according to the preferences of modern festival attendees, thinking of the York and Toronto recreations. If the cycle were run according to the strategy proposed here but beginning at 4:30 am, the pageants would be finished by suppertime, around $6: 30 \mathrm{pm}$, making it possible to have a celebratory communal meal at the conclusion of Corpus Christi festivities.

9 Twycross, 'Forget the 4.30 a.m. Start', 110.

10 See Peter Meredith, 'John Clerke's Hand in the York Register', Leeds Studies in English 12 (1981), 245-71, especially 255-9. 
11 Margaret Dorrell, 'Two Studies of the York Corpus Christi Play', Leeds Studies in English ns 6 (1972), 95.

12 Johnston, 'The Plays of the Religious Guilds of York: The Creed Play and the Pater Noster Play', Speculum 50.1 (1975), 72, https://doi.org/10.2307/2856513. See also Johnston, 'York Cycle 1998: What We Learned', Early Theatre 3 (2000), 202, https://doi.org/10.12745/et.3.1.578.

13 Mike Tyler, 'Revived, Remixed, Retold, Upgraded? The Heritage of the York Cycle of Mystery Plays', International Journal of Heritage Studies 16.4-5 (2010), 324-5, https://doi.org/10.1080/13527251003775679.

14 Dorrell, 'Two Studies', 68.

15 David J.F. Crouch, 'Paying to See the Play: The Stationholders on the Route of the York Corpus Christi Play in the Fifteenth Century', Medieval English Theatre 13 (1991), 65.

16 Alan H. Nelson, 'Principles of Processional Staging: York Cycle', Modern Philology 67.4 (1970), 303-20, https://doi.org/10.1086/390184.

17 Martin Stevens, 'The York Cycle: From Procession to Play', Leeds Studies in English ns 6 (1972), 37-61.

18 Crouch, 'Paying to See the Play', 97.

19 Johnston, 'The Creed Play and the Pater Noster Play'.

20 Johnston, 'York Cycle 1998', 199.

21 Mike Tyler, 'The Pageant Master's Overview', in The York Mystery Plays: Performance in the City, ed. Margaret Rogerson (York, 2011), 116-23. The 2006 and 2010 York productions staged only twelve plays at four stations, and the events took seven hours.

22 Clifford Davidson, ed., The York Corpus Christi Plays (Kalamazoo, 2011), 15.

23 Rogerson, Playing a Part in History, 199.

24 Johnston and Rogerson, eds, REED: York, 1.109.

25 Rogerson, Playing a Part in History, 200.

26 Ibid., 202-3.

27 Plays (and wagons) 5, 6, 7, and 8: 'The Fall', 'The Expulsion from the Garden', 'Sacrificium Cayme et Abell', and 'The Building of Noah's Ark'.

28 Plays (and wagons) 9, 10, 11, and 12: 'The Flood', 'Abraham and Isaac', 'Pharaoh and Moses', and 'The Annunciation to Mary and the Visitation'.

29 As even the longest individual York pageant is relatively short compared to any stand-alone medieval play, there seems to be an implicit assumption that none of the York pageants were cut for length. Cutting text from longer pageants would, in the simplest and most direct way, bring them in line with the pageants adjoining them 
in the performance sequence. See Meredith, 'John Clerke's Hand', on the frequency of guild revisions to pageant texts.

30 Personal communication, 13 March 2015.

31 I am indebted to Gloria J. Betcher for this insight.

32 Johnston and Rogerson, eds, REED: York, 2.732.

33 V.A. Kolve, The Play Called Corpus Christi (Stanford, 1966), 67-70.

34 Ibid., 70-4.

35 Ibid., 79.

36 Johnston and Rogerson, eds, REED: York, 1.8.

37 Ibid., 2.694.

38 Ibid., 1.135.

39 Liberty Stanavage, 'Problematising Textual Authority in the York Register', Essays and Studies 63 (2010), 208.

40 Johnston and Rogerson, eds, REED: York, 2.695.

41 Margaret Rogerson, 'A Table of Contents for the York Corpus Christi Play', in Words and Wordsmiths: A Volume for H.L. Rogers, ed. Geraldine Barnes, John Gunn, Sonya Jensen, and Lee Jobling (Sydney, 1989), 85-90.

42 Some proponents of maximal procession use the city's difficulty in renting Pavement, the final station, as evidence in favour of that model, suggesting that the leasing difficulty stemmed either from exhausted performers or from some pageants failing to make it to that station at all. Either option would seem to be evidence of a failed strategy rather than one that the city would wish to repeat year after year. To reiterate a point made earlier, even if the city could present every pageant at every station (up to seventeen of them), there have been no compelling arguments as to why they would have found such a goal desirable when it resulted in exhausted performers and unleased stations.

43 Crouch, 'Paying to See the Play', 98. 